\title{
A post-gene silencing bioinformatics protocol for plant-defence gene validation and underlying process identification: case study of the Arabidopsis thaliana NPR1
}

\author{
Rosita E. Yocgo ${ }^{1,2}$, Ephifania Geza ${ }^{1,3}$, Emile R. Chimusa ${ }^{4}$ and Gaston K. Mazandu1,2,3*
}

\begin{abstract}
Background: Advances in forward and reverse genetic techniques have enabled the discovery and identification of several plant defence genes based on quantifiable disease phenotypes in mutant populations. Existing models for testing the effect of gene inactivation or genes causing these phenotypes do not take into account eventual uncertainty of these datasets and potential noise inherent in the biological experiment used, which may mask downstream analysis and limit the use of these datasets. Moreover, elucidating biological mechanisms driving the induced disease resistance and influencing these observable disease phenotypes has never been systematically tackled, eliciting the need for an efficient model to characterize completely the gene target under consideration.

Results: We developed a post-gene silencing bioinformatics (post-GSB) protocol which accounts for potential biases related to the disease phenotype datasets in assessing the contribution of the gene target to the plant defence response. The post-GSB protocol uses Gene Ontology semantic similarity and pathway dataset to generate enriched process regulatory network based on the functional degeneracy of the plant proteome to help understand the induced plant defence response. We applied this protocol to investigate the effect of the NPR1 gene silencing to changes in Arabidopsis thaliana plants following Pseudomonas syringae pathovar tomato strain DC3000 infection. Results indicated that the presence of a functionally active NPR1 reduced the plant's susceptibility to the infection, with about 99\% of variability in Pseudomonas spore growth between npr1 mutant and wild-type samples. Moreover, the post-GSB protocol has revealed the coordinate action of target-associated genes and pathways through an enriched process regulatory network, summarizing the potential target-based induced disease resistance mechanism.

Conclusions: This protocol can improve the characterization of the gene target and, potentially, elucidate induced defence response by more effectively utilizing available phenotype information and plant proteome functional knowledge.
\end{abstract}

Keywords: Gene silencing, Plant defence gene discovery, Semantic similarity, Arabidopsis thaliana, Pseudomonas syringae

*Correspondence: kuzamunu@aims.ac.za

${ }^{1}$ African Institute for Mathematical Sciences (AIMS), AIMS South Africa and

AIMS Ghana, Cape Town, South Africa

²Biomathematics Division, Department of Mathematical Sciences,

Stellenbosch University, Stellenbosch, South Africa

Full list of author information is available at the end of the article 


\section{Background}

Plants are sessile organisms often subjected to several attacks and invasions from herbivorous and pathogenic organisms. Pathogenic organisms have been repeatedly reported to cause outbreaks on bean, cucumber, stone fruit, kiwi and olive tree, as well as on other crop and noncrop plants [1]. Plants respond to these attacks by switching on an array of defence pathways whose end products serve to limit the progression of invading pathogens. The innate response is the first stratum and earliest form of response reported. It involves interaction between pathogen associated molecular patterns (PAMP/MAMP) from the invading pathogen, and the plant's membranelocalized pattern recognition receptors [2-4]. Downstream of this is the hypersensitive response (HR) which is highly specific and requires the recognition of specific avirulent genes from the pathogen by specific resistance (R) genes in the plant $[5,6]$. Further downstream is a broad spectrum-type of response called systemic acquired resistance (SAR), a long-lasting defence response which primes the plant against future pathogenic attack [2, 7]. In 1999, Pieterse and Van Loon [8] highlighted the existence of yet another form of systemic response called induced systemic response (ISR), which can occur independently of the HR and SAR.

These strata of defence response pathways are generally governed by perturbations in the cells redox state, fluctuations in intracellular ionic concentration, activation/repression of kinases, synthesis of diverse signalling molecules, including salicylic acid (SA), jasmonic acid (JA), ethylene (Et), activation/repression of transcriptional co-regulators, such as the non-expressor of pathogenesis-related 1 (NPR1), activation/repression of transcription factors, such as TGA and WRKY, and the ultimate expression/suppression of defence end products, such as pathogenesis-related (PR) proteins, which influences the growth and progression of the invading pathogens [9-14]. Understanding the biology of the plant protection and defence response may help in controlling the performance and survival of plants, which are very often faced with several types of stresses. The induced resistance response requires a coordinate action of many defence-related genes interacting within processes and signalling pathways to control down-stream responses during stress conditions. Computational modelling is therefore playing an additional role [15] in improving our understanding of plant defence and disease resistance mechanisms in a manner that is less costly, reduces redundancies and increases robustness. Such models offer attractive alternatives for the identification of gaps and opportunities in already characterized biological systems, and could eventually inform the design of more targeted molecular biology experiments [16].
Pseudomonas syringae ( $P$. syringae) is a rod shaped Gram-negative bacterium, a major bacterial leaf pathogen that causes diseases in a wide range of plant species with visible symptoms $[17,18]$. A specific variety of $P$. syringae pathovar tomato strain DC3000 (Pst-DC3000), is known to infect DC3000 tomato and Arabidopsis thaliana plants [19], using the plant leaf surface to negotiate its entry into the plant. Both Arabidopsis [20] and Pst-DC3000 [19] have been sequenced and are genetically tractable, economically and environmentally convenient, and constitute a model system in research for studying molecular pathogenesis and dynamics of plant-pathogens interactions [21]. Interestingly, Arabidopsis thaliana shares high similarity with high agronomic value crops, such as rice with similarity of 0.71 [22], suggesting that the findings related to Arabidopsis thaliana can be assessed to determine whether they could be applied to these different plants.

In this study, we used NPR1 (or SAI1 for salicylic acid-insensitivity or NIM1 for non-inducible immunity) as a reference due to the available experimental data and its central role in SAR signalling pathway, a broadspectrum resistance protecting against several pathogenic attacks [23], which activates antimicrobial genes products in both the model plant Arabidopsis thaliana and a diverse number of food crops [4, 24-32], including canola, cabbage, broccoli, tobacco, tomato, potato, corn. NPR1 is also involved in the regulation of signalling pathways like abscisic acid (ABA) [33], which, as JA- and Et-dependent activation of defense responses resulting from ISR [17], offers resistance to necrotrophic pathogens. We propose a post-gene silencing bioinformatics (post-GSB) protocol, a two-step approach (see Fig. 1), which can be used to efficiently analyze plant differential responses based on leaf spore count or expression level experimental data sets. This post-GSB protocol introduces the closeness score concept between plants to extract differentially infected plants in a population of Arabidopsis thaliana wild type and npr 1 mutant plants infected with Pst-DC3000 used in further analyses. It uses a Gene Ontology (GO) based semantic similarity model to identify proteins collaborating with NPR1 as well as enriched biological processes involved in the defence response and elucidate these process occurrence sequences. This new model manages eventual uncertainty of data, potential noise inherent in the experiment and redundancy from the semantic-based GO structure to effectively assess contributions of and validate plant-defence genes, and predict plant-defence mechanisms.

\section{Methods}

The study was divided into two parts, the first was to check whether NPR1 plays an important role in plant protection and secondly to perform functional analyses 


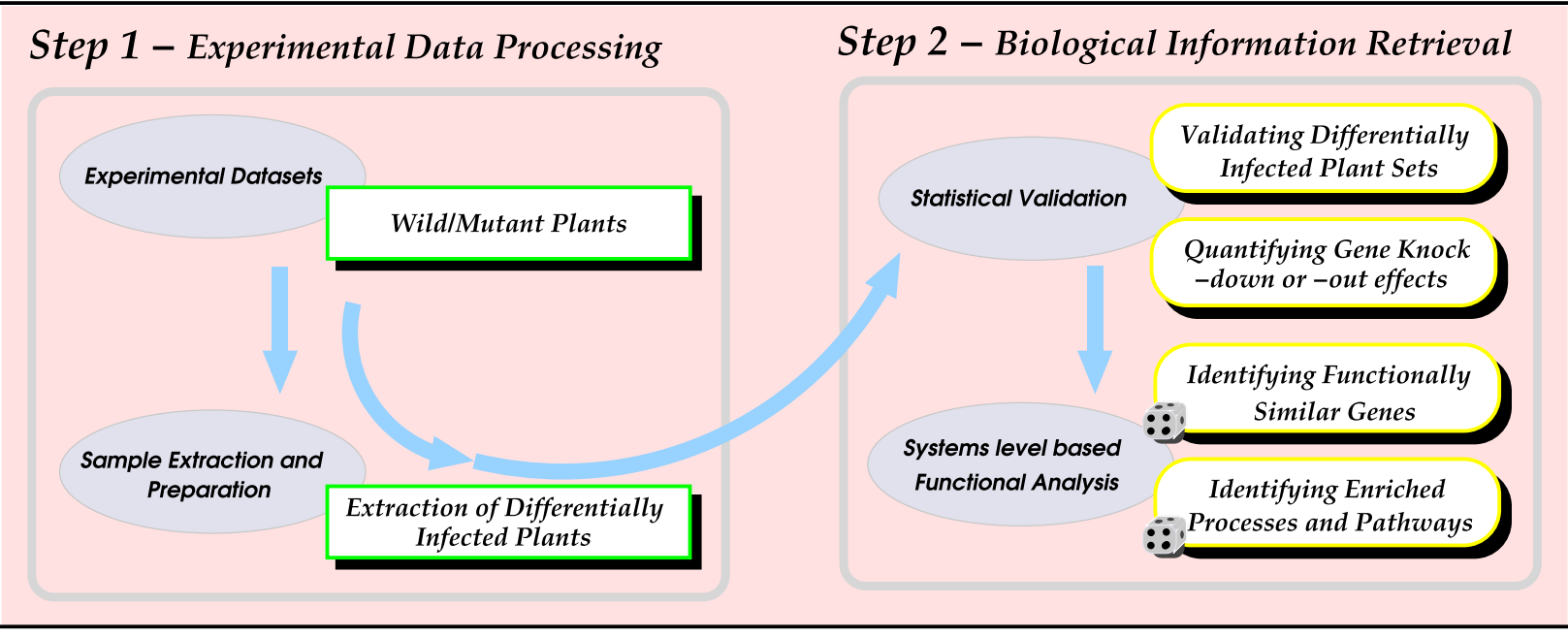

Fig. 1 The post-gene silencing bioinformatics (post-GSB) scheme. This describes the two steps of the model as described in the scheme. The first step consists of producing experimental data sets and using the closeness scores between plants to extract the set of differentially infected plants to be considered for further analyses. The second step initially focuses on statistical analyses checking whether there is any difference between the two data sets: wild type and npri gene mutant plants. If this difference is significant, then the Gene Ontology process annotation based functional analysis is performed to identify proteins, enriched processes and pathways contributing to the NPR1-based plant defence mechanisms

to predict the biological mechanisms of the NPR1-based defence response.

\section{Experimental data from Arabidopsis wild type and npr1 mutant plants}

Data analyzed in this study was derived from a study conducted at the John Innes Centre (England) in 2010 [32] and consisted of data from wild type (Wt) and npr1 mutant Arabidopsis thaliana Columbia $(\mathrm{Col}-0)$ plants 48 hours post infection with Pst-DC3000 [34]. These plants were grown and inoculated under controlled greenhouse conditions $\left(23^{\circ} \mathrm{C}, 10 \mathrm{~h}\right.$ day $/ 14 \mathrm{~h}$ dark regime and a relative humidity of $65 \pm 5 \%$ ) in the John Innes Centre in England [32]. Pst-DC3000 bacteria strain was cultured as described in [34] using King B's media [ $20 g L^{-1}$ proteose peptone (w/v), $1.5 g L^{-1}$ di-potassium hydrogen phosphate $(\mathrm{w} / \mathrm{v}), 1.5 \mathrm{gL} \mathrm{L}^{-1}$ magnesium sulphate $(\mathrm{w} / \mathrm{v}), 1.5 \%$ glycerol $(\mathrm{v} / \mathrm{v})$ and $1.2 \%$ bacterio agar $(\mathrm{w} / \mathrm{v})]$ supplemented with $50 m g L^{-1}$ kanamycin. The bacteria cells were resuspended in a $10 \mathrm{mM} \mathrm{MgCl}$ solution and the concentration adjusted to $5 \times 105$ colony forming unit $c f u . m L^{-1}$. For each plant to be inoculated, three leaves were handinfiltrated using a $1 \mathrm{~mL}$ needless syringe containing either a $10 \mathrm{mM} \mathrm{MgCl}$ solution or an inoculum of Pst-DC3000 $\left(5 \times 105 \mathrm{cfu} . m L^{-1}\right)$. Bacteria growth was measured as spore counts $48 \mathrm{~h}$ post treatment using $8 \mathrm{~mm}$ leaf discs excised from the treated plants. Measurements were conducted using a FB12 luminometer with a single photon counter [32, 34]. For adequate representation and statistics purposes, the experiment was conducted three times using a total of 60 plants (three infected leaves per plant) per genotype (see raw data in Additional file 1).

\section{Sample extraction and analysis}

Data from a total of 31 Arabidopsis Wt plants (controls) and 29 npr1 mutant plants (cases) inoculated with PstDC3000 were used for further analysis. Figure 2 is a graphical representation of the spore count data to visually assess the distribution of these spore counts. Noticing that there was a distribution pattern, samples were further analysed in three main steps: (1) computing the closeness score of each individual in a sample and ranking these individuals based on these scores; (2) extracting the list of differentially infected plants using Pearson $\chi^{2}$ scores based on aggregated closeness scores; and (3) statistically measuring the significant difference among the two phenotypes.

\section{Computing individual closeness scores}

Generally, a set of plants within each group consists of a mix of phenotype tendency associated with different levels (moderate or high) of infection observed through plant spore counts. Since at a higher level of infection, it may not be evident to distinguish between the two groups under consideration, there is a need for a scoring scheme which can appropriately classify plants with moderate level of infection, referred to as differentially infected plants, based on plant spore counts. Here we set up a closeness score approach to measure the length of the line-segment joining the plant phenotypes using 


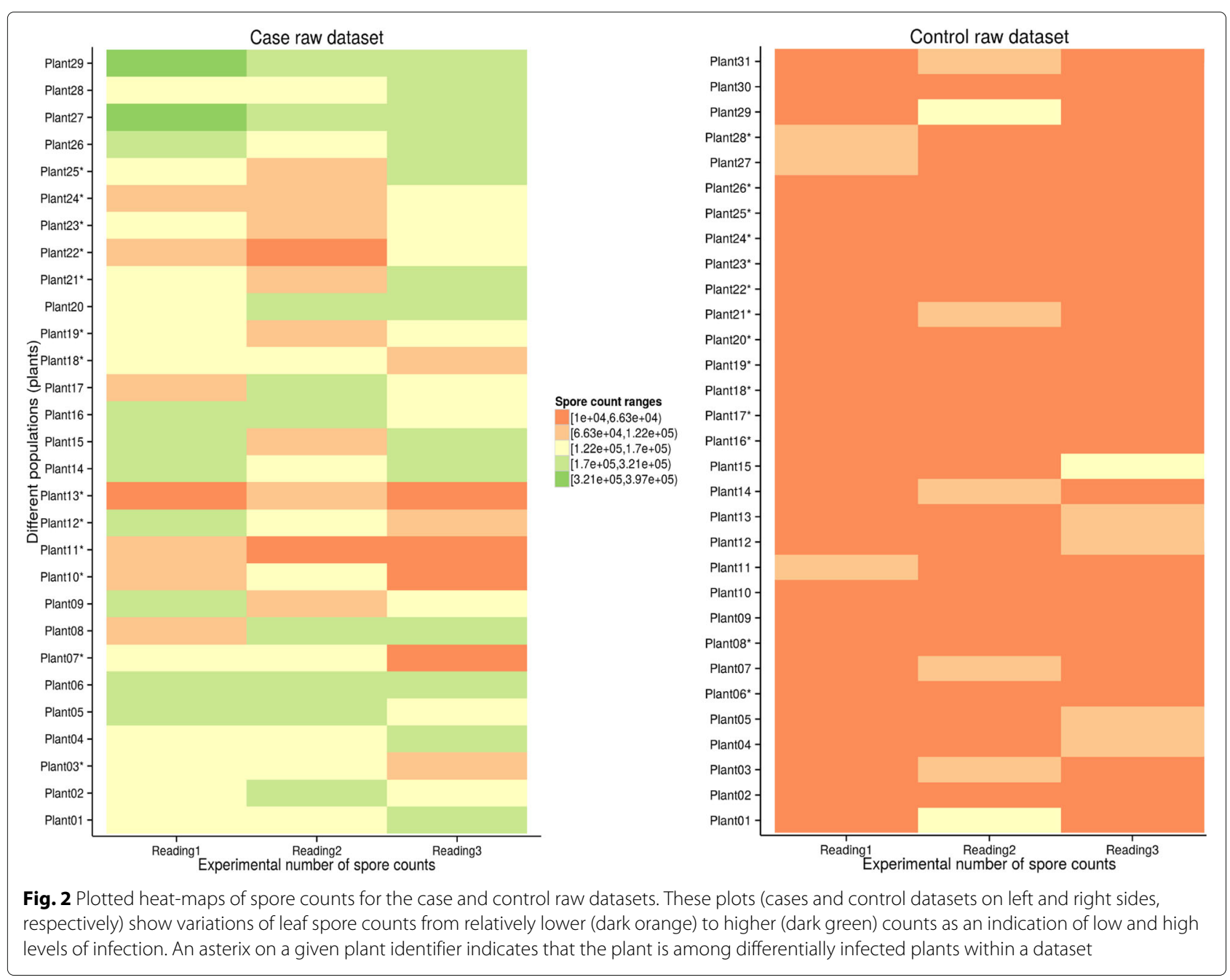

spore count vectors, enabling the selection of differentially infected plants. The individual closeness score of an individual (plant) $l$, denoted $\operatorname{ICS}(l)$, in a sample is computed as follows:

$$
\operatorname{ICS}(l)=\sum_{j=1}^{n} \mathcal{S}_{l J}
$$

where $n$ is the size of the sample (number of individuals in the sample) and $\mathcal{S}_{l}$ is the similarity score between individuals $l$ and $J$ calculated using the Manhattan metric defined on a vector of spore counts for three different readings and converted to similarity measure following the Resnik-edge-based approach [35, 36]. This similarity score $\mathcal{S}_{l J}$ is given by:

$$
\mathcal{S}_{l J}=2 \times \delta\left(x_{l}\right)-d\left(x_{l}, x_{J}\right)
$$

with $x_{k}$ a spore count vector of individual $k, \delta\left(x_{l}\right)=$ $\max \left\{d\left(x_{l}, x_{J}\right): j=1, \ldots, n\right\}$ and $d\left(x_{l}, x_{J}\right)$ the distance between spore count vectors of the two individuals based on the Manhattan metric defined on a vector of spore counts, computed as follows:

$$
d\left(x_{l}, x_{\jmath}\right)=\min \left\{\sum_{k=1}^{n}\left|x_{l k}-x_{\jmath p(k)}\right|: p \in \mathcal{P}\right\}
$$

where $\mathcal{P}$ is the set of all permutations of the ordered set $S=\{1,2, \ldots, n\}$ of $n$ readings in the sample. The individual or plant with the highest ICS is referred to as reference individual or plant, whose similarity scores to other plants are used to extract the set or list of plants of interest for further statistical analyses.

\section{Extracting sets of differentially infected plants in different samples}

In order to minimize the impact of potential biases which may emanate from highly infected plants, we design a model for selecting sets of differentially infected plants in which spore counts based phenotypes are significantly associated with moderate level of infection in different samples based on closeness or similarity score described in the subsection above. Using similarity scores between 
reference plant, denoted $d$, and all plants in a sample, the list of these plants were ranked from the highest to the lowest scores. The ranked plant list is then used to compute a Pearson $\chi^{2}$ score for each plant subset, reflecting the tendency of plants in a particular set to occur towards the extremes of the list. The Pearson $\chi^{2}$ score of a subset containing plants re-indexed from $\ell$ to $m$, denoted $\chi_{P}^{2}(\ell, m)$, is given by:

$$
\chi_{P}^{2}(\ell, m)=\sum_{J=\ell}^{m} \frac{\left(\mathcal{S}_{d_{J}}-\mu_{\ell m}\right)^{2}}{\mu_{\ell m}}
$$

which is known to approximate a $\chi^{2}$-distribution with $(m-\ell)$ degree of freedom (dof) and where their expected value $\mu_{\ell m}$ represents aggregated score (ES) of the extracted subset and estimated as follows:

$$
\mu_{\ell m}=\mathrm{ES}(m-\ell+1)=\sum_{J=\ell}^{m} \mathcal{S}_{d_{J}}
$$

We identified $s$ top individuals as differentially infected with $s$ the index fold-change $\chi_{P}^{2}$. Assuming that the ranked list contains $n$ individuals, $s(s \leq n)$ is the smallest index satisfying the following inequality:

$$
\frac{\chi_{P}^{2}(1, s)-r * \chi_{P}^{2}(s+1, n)}{\sqrt{1+r^{2}}}>0
$$

where

$$
r=\sqrt{\frac{s-1}{n-s-1}}
$$

which is the ratio of standard deviations of $\chi_{P}^{2}(1, s)$ and $\chi_{P}^{2}(s+1, n)$, and set to 1 if $s=1$.

The significance of the aggregated score, ES $(s)$, of the subset of differentially infected plants was assessed using sample randomization. So, we randomly selected 1000 independent subsets (same size with the set of differentially infected) of plants and compute ES of each subset and then perform the Shapiro-Wilk test under the null hypothesis that the generated sample is drawn from a normal distribution. Following the rejection or the acceptance of the null hypothesis, we perform the Wilcoxon- or the T-test to check whether the identified set of differentially infected individuals is more than expected by chance.

\section{Statistical analyis of npr 1 mutant and wild-type plant based disease symptoms}

The contribution of NPR1 protein to the plant protection during infection as the defence co-regulator is statistically assessed on sets of differentially infected plants extracted from the two population samples (mutant/case and wild/control). We test for the differences between the mutant and the wild type plants using parametric or non parametric statistics given that agreements with respects to the violations of the assumptions are met. Thus, the normality and variance homogeneity assumptions of the two samples are tested using the Shapiro-Wilk and Bartlett tests, respectively. In order to satisfy these assumptions for datasets which are characterized by extreme nonnormality or heterogeneity of variance, we apply a data transformation $[37,38]$ based on the Fisher-Pearson coefficient of skewness [39] to bring the data into greater agreement with the normality and variance homogeneity assumptions. Depending on whether normality and variance homogeneity assumptions are met or not, we performed the analysis of variance (ANOVA) method or the non-parametric Kruskal-Wallis rank sum test.

\section{Bioinformatics analysis of potential NPR1-based plant defence mechanisms}

We used the Gene Ontology (GO) [40, 41] and the protein GO Annotation (GOA) mapping provided by the UniProtKB-GOA project [42-44] to reveal the potential NPR1-based regulatory network using enriched biological processes and pathways in which a set of protein targets are involved. The complete set of GO data and proteinGO term associations were extracted from the GO and GOA databases, respectively, accessed on the 11th of October, 2016. For the pathway enrichment analysis, we use the Kyoto Encyclopeadia of Genes and Genomes (KEGG) datasets. The whole Arabidopsis thaliana pathway dataset was extracted from the KEGG database at http://www.genome.jp/kegg/.

\section{Identification of other putative proteins participating to the plant defence response}

Proteins perform an astonishing range of biological functions in an organism by collaborating in pathways and processes, and interacting with the cellular environment in some way to promote the cell's growth and function $[45,46]$. This argues that the induced resistance response requires concerted biological action of many genes involved in diverse processes or defence signalling pathways. There are various computational approaches for identifying proteins co-working or involved in a similar process, which, in general, rely on a priori knowledge of protein functional features. This functional knowledge can be either a protein-protein interaction (PPI) network, in which case, these proteins interact and influence each other in the same sub-network or protein functional annotations, in which case, these proteins are involved in semantically similar processes or in the same pathway. In this study, since we are looking at the NPR1 biological role and functional annotations, we use protein biological process dataset to identify putative proteins which are functionally similar to Arabidopsis NPR1 by quantifying functional similarity between proteins based on sets of strict non-redundant processes annotating proteins under consideration [47]. 
Given two proteins $p$ and $q$, the functional similarity between $p$ and $q$, BMA $(p, q)$, is computed using the Best Match Average model [48-51] as follows:

$$
\operatorname{BMA}(p, q)=\frac{1}{2}\left(\frac{1}{n} \sum_{s \in T_{p}} \mathcal{S}\left(s, T_{q}\right)+\frac{1}{m} \sum_{s \in T_{q}} \mathcal{S}\left(s, T_{p}\right)\right)
$$

where $T_{r}$ is a set of process terms annotating a given protein $r$ and $n=\left|T_{p}\right|$ and $m=\left|T_{q}\right|$ are the number of processes terms in these sets. $\mathcal{S}\left(s, T_{r}\right)=$ $\max \left\{\mathcal{S}(s, t): t \in T_{r}\right\}$ with $\mathcal{S}(s, t)$, the semantic similarity score between process terms $s$ and $t$ computed using the GO-universal metric [48]. It is worth noting that semantic similarity measure has proved its effectiveness to solving biological issues related to the Gene Ontology annotation-based knowledge discovery, including predicting and validating protein-protein interaction (PPI) [52]. With curated PPIs, which are still relatively scarce, high-throughput biology experiments and computational methods producing high rate of false positive PPIs [53], and the lack of appropriate techniques to address these shortcomings [45], semantic similarity-based approach is more effective, providing a classification indicator of PPIs in the absence of reliable information.

\section{Identifying enriched Arabidopsis defence response processes and pathways}

For process or pathway enrichment analysis, we used hyper-geometric test adjusted using the Bonferroni multiple testing correction. For each process or pathway, the $p$-value was calculated using its frequencies of occurrence in the reference dataset (Arabidopsis thaliana proteome) and target set, which composed of proteins identified to be functionally similar to NPR1. Thus, this $p$-value, which is the probability of observing at least $s$ proteins from a target gene set of size $n$ by chance, knowing that the reference dataset contains $m$ annotated genes out of $\mathrm{N}$ genes, is given by the following formula $[54,55]$ :

$$
P[X \geq s]=1-\sum_{k=0}^{s-1} \frac{\left(\begin{array}{c}
m \\
k
\end{array}\right)\left(\begin{array}{c}
N-m \\
n-k
\end{array}\right)}{\left(\begin{array}{l}
N \\
n
\end{array}\right)}
$$

where the random variable $X$ is the number of genes involved in the GO process or participating to the pathway under consideration within a given target gene set contributing to plant defence response. To account for relationships between $\mathrm{GO}$ terms in the GO structure, we used the concept of the $\mathrm{GO}$ term semantic similarity score [55] and the frequency of occurrence $f(t)$ of the targetassociated process $t$ in a set of proteins $P$ is given by:

$$
f(t)=\sum_{q \in P} \delta_{q}(t)
$$

where $\delta_{q}$ is the $q$-function indicator given by

$$
\delta_{q}(t)=\left\{\begin{array}{l}
1 \text { if } \mathcal{S}_{q}(t)>\varepsilon \\
0 \text { otherwise }
\end{array}\right.
$$

where $\varepsilon \geq 0$ is the agreement level or customized agreement at which a GO process is considered to be a possible annotation of the protein $q$ and $\mathcal{S}_{q}(t)=\mathcal{S}\left(t, T_{q}\right)$, representing the semantic similarity degree at which a related term is considered to semantically reflect in the specification of the term $t$ [47]. Here, $\varepsilon$ was set to 0 for $t \in T_{q}$ or $t \in \mathcal{A}_{q}$, and to 0.7 for $t \in \mathcal{C}_{q}$ where $\mathcal{A}_{q}$ and $\mathcal{C}_{q}$ are sets of ancestors and descendants of processes in $T_{q}$, respectively. The $p$-value of each process term was adjusted using the Bonferroni multiple testing correction.

\section{Results and discussion}

In the first part of the post-GSB framework developed in this study, we have designed a spore count closeness scoring approach. This enables the identification of differentially infected plants used to ascertain the role of NPR1 in Arabidopsis plant defence response with bacteria spore count data collected from Arabidopsis Wt and npr1 mutant leaves $48 \mathrm{~h}$ post Pst-DC3000 infection as described in the "Methods" section. We then predicted the potential NPR1-based regulatory network based on the identified set of putative proteins, enriched biological processes and pathways which participate in plant defence response.

\section{NPR1 protein is required for Arabidopsis defence response}

The heat map representation of the raw experimental spore count data from both data sets in Fig. 2 revealed that spore distribution patterns in the Arabidopsis Wt infected leaves are more closely similar (see Fig. 2b) in comparison to those of the mutant (Fig. 2a). This is in agreement with previous results which showed a significant difference in spore numbers between the two phenotypes (data not shown) [32]. In a study of Wt and npr1 mutant plants by Cao et al. [56], it was observed that infection spread event to uninfected parts of the leaf is quite rapid due to its high level of susceptibility. To eliminate the possibility that the presence of highly infected plants in the mutant population is contributing significantly to the observed differential response found in this study, we statistically tested the difference between the two groups of plants on specific sets of plants from these two groups. These sets contains only differentially or moderately infected plants in order to keep out the highly infected plants within the two phenotype groups using the closeness scoring approach. Outputs generated 13 moderately infected npr1 mutant plants, and 14 moderately infected Arabidopsis Wt plants which were used for further downstream analysis (Fig. 2, plants marked with an asterisk). Note that these identified sets of differentially infected plants for 
both npr1 mutant and wild-type plants are statistically significant with $p$-values $<2 e-16$.

The graphical representation (Q-Q plots) of the above Wt plant sub-data indicated that this sub-data was not normally distributed (see Additional file 2: Figure S1) with the Shapiro-Wilk test $p$-value of $0.000152 \leq 0.05$, thereby leading to a two-step statistical analysis process. Firstly, we tested for statistical differences using the non-parametric Kruskal-Wallis rank sum test. Results from this test indicated that within phenotypes, there was no significance difference $(p$-value $=0.70>0.05)$, but, between the two phenotypes, there was a significant difference in the number of bacteria spores $(p$-values $=4.551 e-12 \leq 0.05)$. Noting that non-parametric tests have weaker statistical power in comparison to parametric tests, and to further eliminate the possibility of introducing a type II error [57], we applied a parametric approach to increase the robustness of our analysis.

In order to bring different data subsets into agreement with the normality and homogeneity of variance (equal population variance) assumptions, these data subsets were log transformed (see Additional file 2: Figure S2) and scaled using their standard deviations. Note that the choice of $\log 10$ transformation was guided by the FisherPearson skewness coefficient $[37,38]$ of the Wt dataset with a value of 1.46524 , suggesting that its distribution was highly skewed (substantially positive skewness) [39]. The Shapiro-Wilk normality test and the Bartlett variance homogeneity $p$-values were greater than 0.1169 and 0.98 for both Wt and npr1 mutant data subsets. Results from our ANOVA using this log transformed data subsets still confirmed that there was no significance difference within data subsets $(p$-value $=0.481)$, but there existed a significant difference in spore numbers between both phenotypes ( $p$-value $<2 e-16$ ) with the measure of association $\omega=0.98893$. This indicates that $99 \%$ of the variability between Wt and $n p r 1$ mutant samples may be attributed to whether the NPR1 protein is functionally active or not, providing evidence that NPR1 plays a critical role in plant defence response.

In summary, we applied the Pearson $\chi^{2}$-based plant closeness scoring scheme in order to extract specific sets of plants in populations under consideration to be used for further statistical inferences. These experimental data subsets showed evidence that a functional NPR1 is required to limit bacteria growth in Arabidopsis plants. This finding correlates with results from previous studies that have equally demonstrated that the presence of a functional Arabidopsis NPR1 is important in limiting pathogen growth in infected plants $[56,58,59]$, playing a key role in the SAR signalling pathway $[23,58,60]$, the broadspectrum type of response providing defence against secondary pathogens after a primary attack. This Pearson $\chi^{2}$-based plant closeness scoring approach enables the use of more relevant data subsets in further analyses, thus limiting the effect of the eventual uncertainty of these datasets and potential noise inherent in the biological experiment used. This provides an increased robustness of statistical analyses and stronger validation of inferences from experimental datasets.

\section{Elucidating potential NPR1-based enriched process regulatory network}

Similar to other organisms, plants combat the adverse effects of stressors by activating or deactivating various processes and pathways. We therefore applied a semantic similarity based computational model to gene products that are functionally similar to NPR 1 and identify enriched plant defence biological processes using protein GO annotation mapping from the GOA-UniProtKB dataset $[42,44]$ with the reviewed proteins in the Arabidopsis proteome retrieved from the UniProt database [61]. Furthermore, we used the Arabidopsis KEGG pathway dataset to retrieve enriched pathways participating to the NPR1based regulation of Arabidopsis defence response and elucidated the GO-based regulatory network triggered by NPR1.

\section{Identification of NPR1-associated plant defence proteins}

In general, defence mechanism is driven by several gene products that act dependently or independently. In order to identify NPR1-associated plant defence proteins, we computed the functional similarity scores between NPR1 and other 20545 annotated proteins [62] out of 51874 found in the complete list of proteins in the Arabidopsis proteome. In order to avoid over-estimating functional similarity scores between proteins [52], which is induced by the redundant processes from parent-child relations from the GO structure [47], we used the set of filtered non-redundant processes in which proteins are involved. Results indicated that 30 proteins shared high functional similarity to the Arabidopsis NPR1 (Table 1) of which, 25 were reviewed or manually curated (in Table 1 ; protein with status $\checkmark$ ). A hierarchical clustering representation of these 25 annotated proteins together with the Arabidopsis NPR1 protein, which shows functional relatedness between these 26 reviewed proteins, produced two main clusters (Fig. 3) with Cluster 1 comprising of two sub clusters $(1 \mathrm{~A}$ and $1 \mathrm{~B})$. Sub-Cluster $1 \mathrm{~A}$ contains proteins closest to NPR1 (at the maximum distance of approximately 0.245 ) and distant at 0.275 from Sub-Cluster 1B, while proteins in Cluster 2 were the farthest subgroup being distant at 0.375 maximum from Cluster 1 . Proteins in the sub-cluster $1 \mathrm{~A}$ comprised of the NPR1/NIM-1 interacting protein (NIMIN-1), transcription factor proteins (TGA3, WRKY70), Resistance to P. syringae 2 (RPS2), two Enhanced Diseases Susceptibility proteins (EDS1, PAD4) and Mitogen-activated protein kinase kinase 4 (MKK4). 


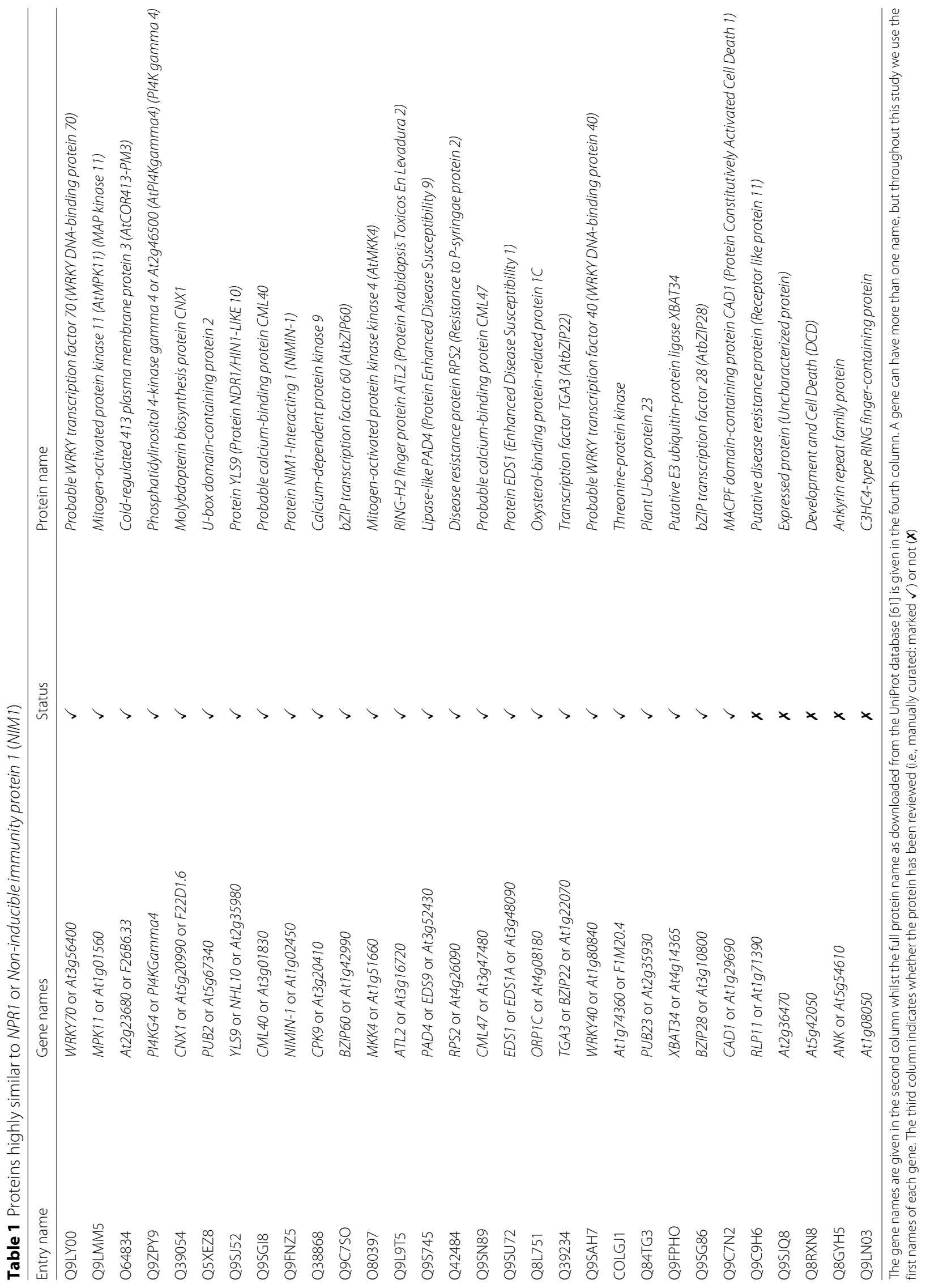




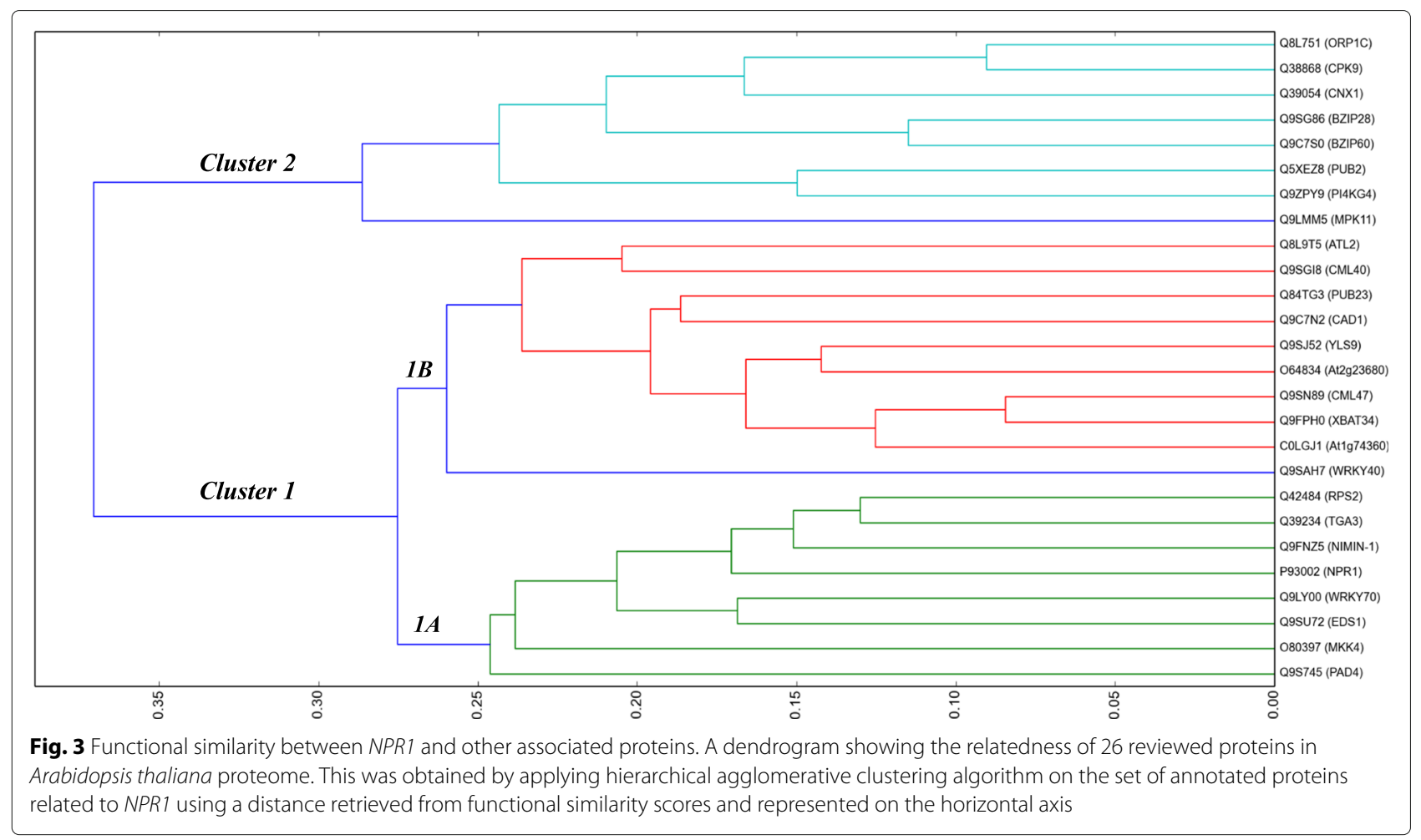

Those in the sub-cluster $1 \mathrm{~B}$ comprised of WRKY40, AT1G74360, XBAT34, the putative calmodulin-like protein 47 (CML47), AT2G23680, the Yellow Leaf-Specific protein 9 (YLS9), Constitutively Activated Cell Death 1 (CAD1), PUB23, CML40, and ATL2. Proteins in cluster 2 comprised of Mitogen-activated Protein Kinase 11 (MPK11), Phosphoinositide 4-Kinase Gamma 4 (PI4KG4), $P U B 2$, two basic Leu zipper (BZIP) transcription factors (BZIP60 and bZIP28), Molybdopterin biosynthesis protein (CNX1), Calcium-dependent Protein Kinase 9(CPK9), and Oxysterol-binding Protein-Related Protein 1C (ORP1C2).

An in-depth literature review demonstrated that these functionally related proteins could contribute in the same pathway as NPR1 or independently to either positively or negatively drive defence response to pathogens and elicitors. For instance, calcium signalling is known to be associated to the innate response, HR and SAR, acting upstream of the pathogen-induced SA-signalling pathway to favor the activation of NPR1 and associated downstream activities, such as TGA binding, to inhibit pathogen growth [63-65]. The calcium signalling triggers the activation of a set of Mitogen protein kinase $(M P K)$ contributing to the plant innate immunity related cell death [66] and the MAMP defence [67], which is also an innate-form of defence response, and to other processes that stimulate ROS production during plant pathogen attack [68]. In this study, two $M P K$ proteins, namely MPK11 (Cluster 2) and MKK4 (Cluster 1A) which is an important mediator of plant response to osmotic stress [69], were found to be closely related to NPR1. Proteins belonging to the EF hand super family have been shown to harbour motifs that are important for calcium sensing $[70,71]$. Typical examples of proteins within this family are the calmodulin (CaM)-like proteins (CML) and Calcium protein kinase $(C P K)[70,72,73]$ whose members: CML47, CML40, CPK9 identified in this study belonged to Clusters 1A and 2. Moreover, two other proteins identified, NDR1 (YLS9) in Cluster 1B and EDS1 in Cluster 1A, are known to mediate the Effector Triggered Immunity through specific $\mathrm{R}$ genes [74, 75]. As illustration, EDS1 was found to be a regulatory gene controlling down-stream defence gene expression in Arabidopsis [76], targeting $\mathrm{R}$ genes with TIR-NB-LRR motifs required for the recognition of Pst-DC3000 avrRps4 proteins [75, 77, 78]. $\mathrm{R}$ genes, such as RPS2 (Cluster 1A), which recognizes Pst-DC3000 avrRpt2, are targeted by NDR1 and harbour LZ-NBS-LRR motifs [74, 75, 77, 78]. YLS9, an NDR1/HIN1-like 10 (NHL-10) identified in our study has been implicated in HR and is inducible by several CPKS [79], thereby suggesting its action downstream of the calcium signalling pathway.

As pointed out previously, proteins functionally related to NPR1 may contribute to the plant defence mechanism degradation. For example, CAD1 (Cluster 1A) has been implicated in the repression of the programmed cell death $(P C D)$ pathway mediated by SA and this negative 
function of $C A D 1$ is inhibited under stress conditions to favor the $P C D$ pathway [80]. However, even under undisturbed conditions, plant proteins undergo proteolysis as a strategy to effectively turnover its protein reservoir and to ensure for efficient functioning of biological processes through an ubiquitination process $[81,82]$. The NPR1 protein, for instance, which can switch between two conformational states (oligomeric and monomeric) or two cell compartments (cytosol and nucleus), is a typical example of a protein whose nuclei-localized monomers undergo proteolysis through a CUL-3-based E3 ligase ubiquitination process to ensure for the effective expression of its target genes $[59,83,84]$. Our analysis identified five putative ubiquitin-like proteins - XBA34, PUB23, PUB2, ATL2, PI4KG4 [85-87]. Although their direct role in NPR1 ubiquitination has not been reported, their transcript levels, especially those of ATL2 and PI4KG4, have been shown to increase following exposure of plants to chitinases [88] and treatment with SA [89], respectively. The role of these proteins during drought stress has equally been demonstrated [85]; and proteins, such as XBAT34 have been shown to be induced by 6-BA (6-benzylaminopurine) and SA [90]. Additionally, XBAT34 contains two Ankyrin repeats, which are also core motifs found in NPR1 protein and are important in mediating interactions with other proteins [58, 90-92]. The importance of the ankyrin repeats within the NPR1 sequence is elegantly demonstrated in the inability of npr 1 mutants to activate PR genes following pathogen attack due to a distortion in this region $[58,93]$. A distorted ankyrin repeat within the $N P R 1$ protein hampers its ability to bind to transcription factors belonging to the basic leucine zipper $(B Z I P)$ family such as TGA3 (Cluster 1A) for a positive defence outcome [92, 94-97].

Two other BZIPs (BZIP60 and BZIP28) were identified in this study and have been implicated in Unfolded Protein Response (UPR) during stress response [98-100]. The ability of the BZIP domain to translocate to the nucleus during stress could be a key contribution to its role during stress responses. In fact, although we did not find a direct relation between BZIP28 and BZIP60 to NPR1 in literature, existing evidence shows that the inositol-requiring protein-1a (IRE1a)/BZIP60 branch of the UPR pathway have a role in PR protein secretion following treatment with SA [99]. In addition to the BZIP transcription factor (TGA3) identified here, proteins belonging to the WRKY family of transcriptional factors [101] - WRKY70 (Fig. 3; Cluster 1A) and WRKY40 (Fig. 3; Cluster 2) were equally identified. Unlike TGA3, no direct interaction between NPR1 and WRKY4O was found during our literature search. However, similar to NPR1 monomers, evidence for the nuclei localization of WRKY40 does exist [102]. Its role in stress response has also been demonstrated and, its ability to interact with other WRKY proteins has been shown $[102,103]$. For instance, co-expression of WRKY18 and WRKY4O led to increased susceptible of plants to $P$. syringae and Botrytis cinerea correlating with reduced PR gene expression [102]. WRKY70 on the other hand is known to positively mediate pathogen defence response in an SA-dependent fashion which is independent of the NPR1 pathway [104]. PAD4, which is another protein identified (Cluster 1A), can act dependently (e.g., for SAdependent defence response) or independently (e.g., for basal immunity [105]) of NPR1 for PR-1 gene expression $[106,107]$. NPR1 also has the ability to interact with nontranscription factors, such as NIMIN-1, identified in this study (Cluster 1A) and experimentally verified to bind to NPR1 $[108,109]$ to modulate PR-1 gene expressions during SAR.

\section{Retrieving enriched processes and pathways mediating the Arabidopsis thaliana plant defence}

A total of 114 biological processes were found to be involved in the Arabidopsis thaliana protection and defence mechanisms, among which 74 were found to be non-redundant considering the feature of the GO structure [47]. 21 processes were identified to be statistically significant in plant defence mechanisms and Table 2 provides a summary of the type of response and biological activities in which these enriched processes are involved. These processes are related to both biotic and abiotic triggered responses, leading to the initiation of major pathways involved in the innate response (GO:0010200), HR (GO:0009626) and SAR (GO:0009862) in plants [2-7]. In general, these processes are triggered on the basis of the (pathogen) attacks classified using the mode of plant-pathogen interactions. For example, a pathogen may survive by using the living plant cells (for biotrophic pathogens) or by killing plant cells and feeding on these dead cells (for necrotrophic pathogens) [110]. Interestingly, the enrichment pathway analysis reveals two enriched KEGG pathways participating to NPR1-associated plant defence response, namely Plant-pathogen interaction (http:// www.genome.jp/kegg-bin/show_pathway?ath04626) and Plant hormone signal transduction (http://www.genome. jp/kegg-bin/show_pathway?ath04075) with $p$-values of 0.013085 and 0.02070 , respectively. These pathways show evidence of regulating a wide variety of enriched biological processes, including programmed cell death (PCD) and defence, HR, ABA and SA dependent responses.

NPR1-associated plant defence proteins share six processes, namely MAPK cascade (GO:0000165), SAR, SA mediated signalling pathway (GO:0009862), Regulation of plant-type hyper-sensitive response (GO:0010363), Protein targeting to membrane(GO:0006612), Defence response to fungus (GO:0050832) and Negative regulation of defence response (GO:0031348). The number of processes in 


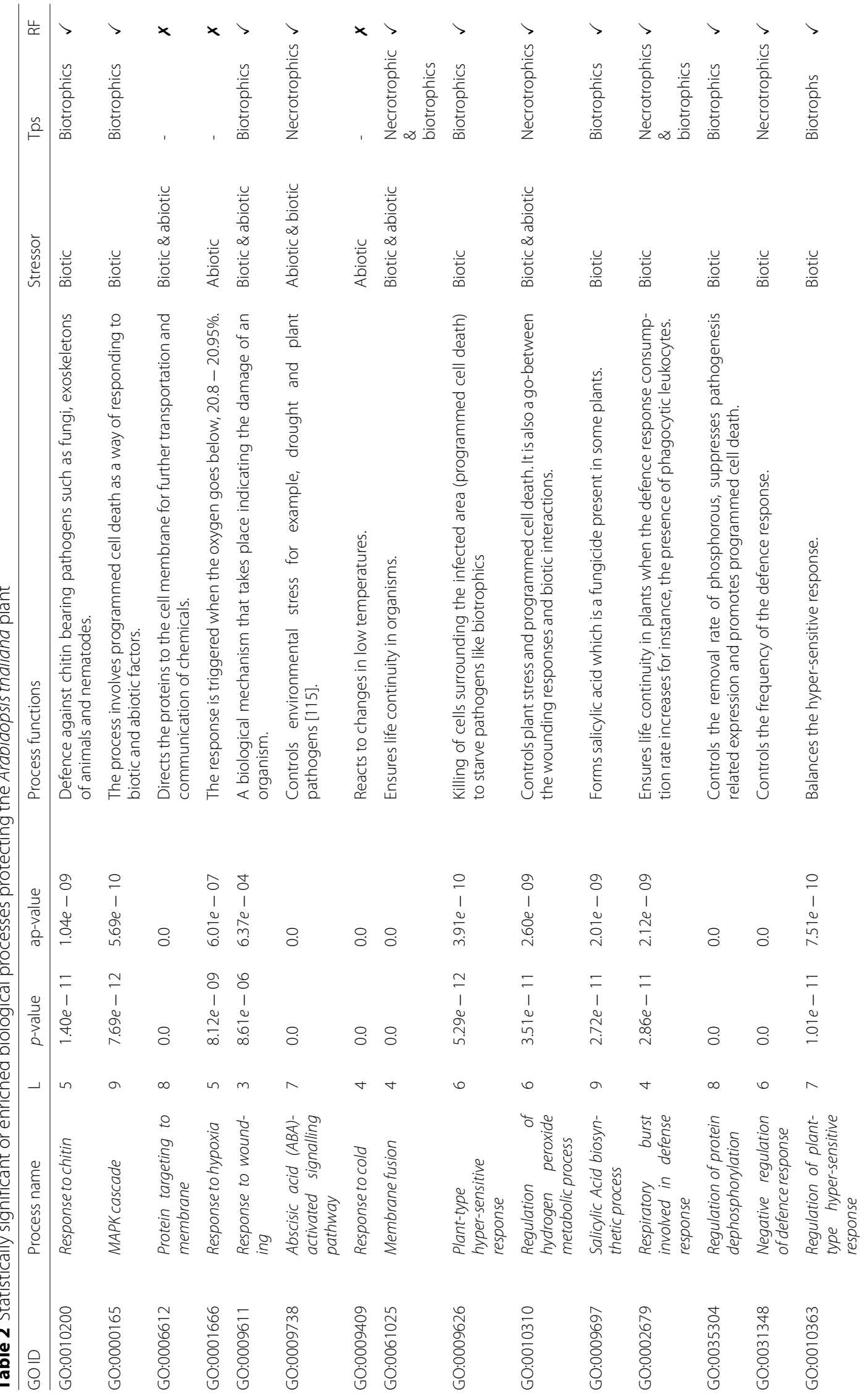




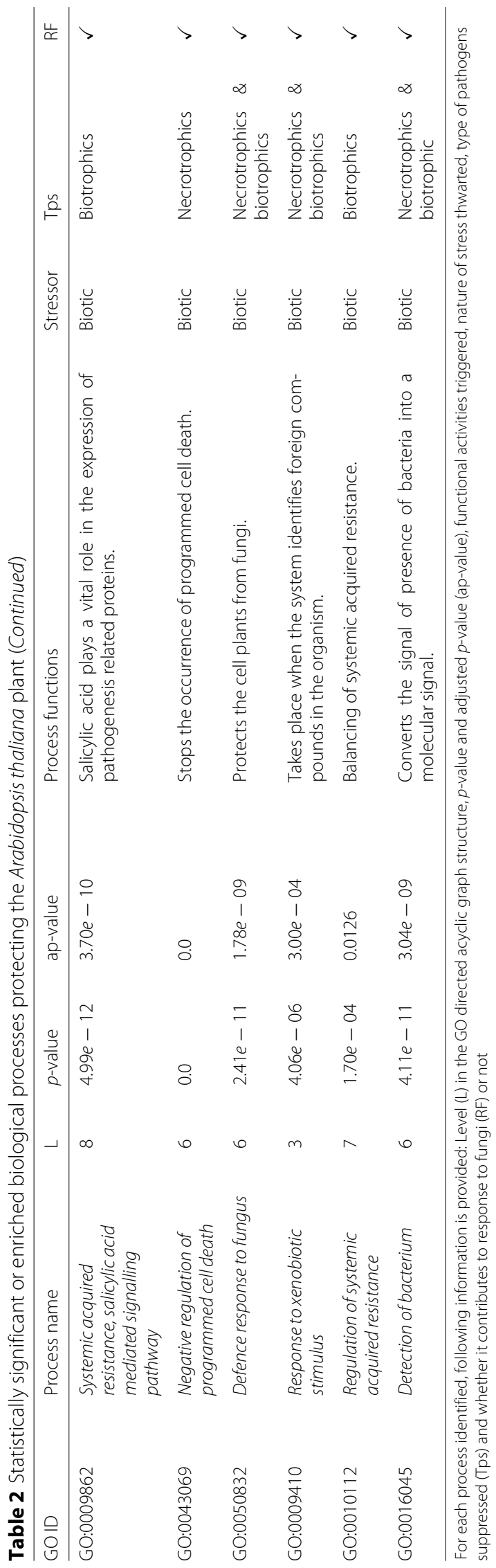


which each protein is contributing is shown in Fig. $4 \mathrm{~b}$ and a, highlighting different protein-process associations. Interestingly, NPR 1 is involved in all 21 enriched processes identified, suggesting that NPR1 is a potential regulator of the plant ubiquitin proteolytic system during infection, controlling associated protein expression levels and functioning at the cross-roads of several signalling pathways, as well as modulating antagonistic cross-talk between different signalling pathways $[83,97]$ critical to the plant defence-mediated response. This suggests that the success of the plant defence mechanism is a result of these different concerted and controlled signal transduction events that sequentially occur in the plant system, leading to an increased resistance to diverse attacks. As a consequence, the failure of these processes to function properly may yield increased susceptibility to the pathogen, which possibly negotiates its entry into the cell by activating processes to thwart plant defence mechanisms. Thus, we built a potential enriched process-based regulatory network using the following binary relation rule: Given two processes $s$ and $t$, the process $t$ is triggered after the process $s$, which is indicated in the regulatory network by an arrow from s to $t$, if $A_{t} \subset A_{s}$ and $A_{s} \supseteq \mathcal{P}$. Under the assumption that a process is triggered after another as a result of specific degradation of a single or a subset of proteins, and where $A_{x}$ is the set of proteins participating to the process $x$ and $\mathcal{P}$ is the set of proteins in at least one of the enriched pathways identified.

Figures $4 \mathrm{c}$ and $\mathrm{d}$ show a potential enriched processbased regulatory network constructed and process frequencies (number of proteins annotated by each process), respectively. This regulatory network reveals, for example, that there are only five possible processes that may be triggered following the occurrence of the negative regulation of PCD (GO:0043069), namely: Response to xenobiotic stimulus (GO:0009410), Membrane fusion (GO:0061025), Plant-type hyper-sensitive response (HR) (GO:0009626), Abscisic acid (ABA)-activated signalling pathway (GO:0009738) and Response to cold (GO:0009409) processes. Most of these processes are expected to occur after the occurrence of the negative regulation of $P C D$, which could be triggered after the occurrence of processes, such as Negative regulation of defence response (GO:0031348). This is consistent as the system may trigger mechanisms susceptible to promote or normalize the plant defence response by coordinating different actions in order to offer appropriate response to and to contain the infection. For example, $\mathrm{HR}$ and ABA-activated signalling pathway may relaunch new PCD by killing the infected cells at the point of invasion $[2,6,7,111]$. This regulatory network also reveals that the occurrence of the negative regulation of $P C D$ can result from the dysfunction of critical processes, such as MAPK cascade (GO:0000165), Protein targeting to membrane (GO:0006612) and regulation to hydrogen peroxide (GO:0010310), which are vital for the regulation of a wide variety cellular activities, including transportation and communication of chemical materials, proliferation, differentiation, apoptosis and stress response [112].

\section{Conclusions}

This study proposes a novel bioinformatics protocol that can be readily applied to plant phenotype based gene knock-out or -down experimental dataset to assess the contribution of the gene under consideration to plant-defence mechanisms and to build a potential enriched biological process-based regulatory network using publicly available biological data. This protocol enables the extraction of the specific (differentially infected) samples of the experimental dataset to eliminate potential artefacts, such as uncertainty of the data set and potential noise inherent in the experiment, which could mask downstream analysis. We applied the protocol to the phenotype dataset expressed in terms of leaf spore counts of $60 \mathrm{npr} 1$ gene mutant and wild-type Arabidopsis thaliana plants following PstDC3000 infection. Results obtained still showed that NPR1 plays an important role during plant pathogen response by suppressing the growth of the pathogen. More specifically, we found that differences in the plant susceptibility to the Pst-DC3000 infection depend on whether the NPR1 protein is functionally active or not with about 99\% of variability in Pseudomonas spore growth between npr1 mutant and Wt plant samples. The increased disease susceptibility phenotypes observed in $n p r 1$ mutant plants following to Pst-DC3000 infection may be due to the fact that the SAR signalling pathway, which is essential for plant defence response, is blocked in these plants as a result of knocking out or down the protein NPR1, leading to the attenuation of PR gene expressions. This SAR signal requires a functionally active $N P R 1$, which is a key regulatory protein of SAR, acting as a controller and modulator of PR gene expressions.

With the increasing number of publicly available biological data which already demonstrates the complexity of the plant defence network, new computational approaches are essential to provide an easy-to-analyse picture which can lead to the identification of gaps and opportunities for the development of future 'wet or dry lab' experiments. The proposed protocol uses the GO-universal metric based Gene Ontology semantic similarity model to identify putative proteins collaborating with NPR1 in regulating plant defence mediated response and retrieve enriched biological processes involved. We identified 26 NPR1-associated plant defence proteins and 21 highly specific processes, which related to the major forms of defence processes reported (innate response, HR, SAR, etc.), and construct the 


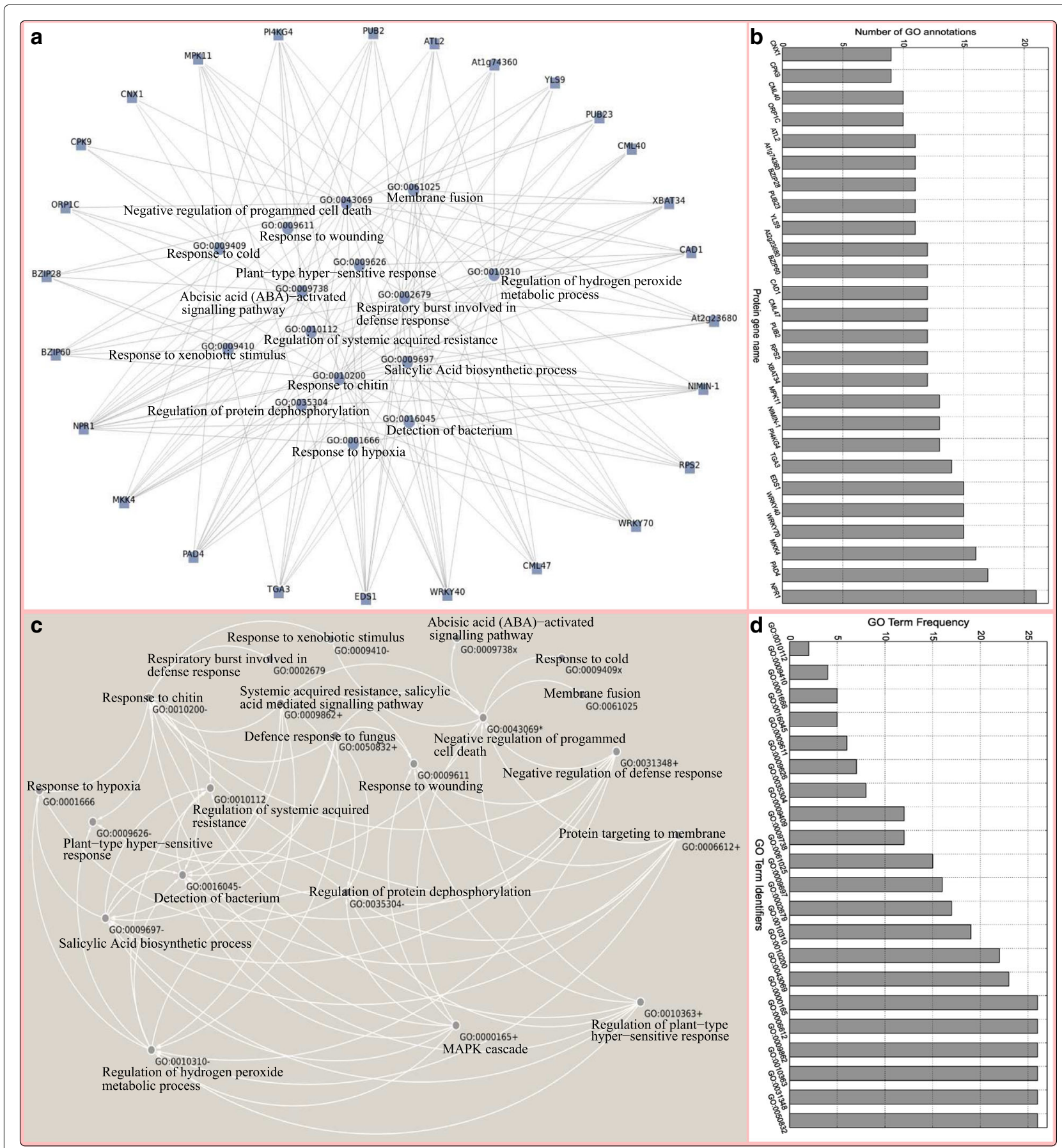

Fig. 4 Summary results of the biological mechanism of the NPR1-based defence response. a plotted using the PINV tool [113] is a protein-process map showing NPR1-associated plant defence proteins and enriched processes in which they are involved, and the number of enriched processes in which each protein is involved is shown in (b). Note that processes in which all proteins are involved are not displayed in (a) to avoid that high number of links limits visibility. c plotted using the Cytoscape tool [114] displays NPR1-based process regulatory network, showing possible process occurrence sequences and (d) shows the number of proteins involved in or frequency of each enriched process. The suffix $+, *, x$, or - were added to enriched process according to the fact all NPR1-associated plant defence proteins are involved in the process (+), or set of proteins involved in the process contains all NPR1-associated plant defence proteins are implicated in the Plant-pathogen interaction ( $\mathrm{x}$ ) or Plant hormone signal transduction (-) or both $(*)$ pathways 
potential process-based regulatory network, predicting occurrence sequences of different processes. This NPR1based enriched process regulatory network (Fig. 4c) can effectively reveal eventual sequences of biological processes occurring during the plant defence response. As illustration, it suggests that the suppression of the SAR signalling pathway (GO:0009862) may thwart processes that enable the detection of the pathogen (GO:0016045), control plant stress, promote PCD and attenuate PR gene expressions (e.g., GO:0010310, GO:0035304) to favor processes leading to the negative regulation of $P C D$ (GO:0043069) in order to trigger processes that possibly ensure pathogen life continuity within plant cells. Different results obtained demonstrate that this novel protocol is effective for assessing plant-defence genes and may help better understand the plant defence mechanisms, an important aspect in the biology of plants.

\section{Additional files}

Additional file 1: Experimental data from Arabidopsis wild type and npr1 mutant plants. Leaf bacteria spore count (phenotype) dataset of 31 Arabidopsis wild type (control) and $29 \mathrm{npr} 1$ mutant (case) plants $48 \mathrm{~h}$ post Pst-DC3000 infection. (XLS $10 \mathrm{~kb}$ )

Additional file 2: Checking normality assumption using Q-Q plots. Checking normality assumption for initial and transformed differentially infected wild and npr 1 mutant plant spore count datasets using Q-Q plots. (PDF $536 \mathrm{~kb})$

\begin{abstract}
Abbreviations
ABA: Abscisic acid; ANOVA: Analysis of variance; DCD: Development and cell death; dof: Degree of freedom; ES: Aggregated score; Et: Ethylene; GO: Gene ontology; GOA: Gene ontology annotation; HR: Hypersensitive response; ICS: Individual closeness score; ISR: Induced systemic response; JA: Jasmonic acid; KEGG: Kyoto Encyclopeadia of genes and genomes; NPR1: non-expressor of pathogenesis-related 1; P. syringae: Pseudomonas syringae; PAMP/MAMP: Pathogen associated molecular patterns/microbe-associated molecular pattern; PCD: Programmed cell death; post-GSB: Post-gene silencing bioinformatics; PPI: Protein-protein interaction; PR: Pathogenesis-related; Pst-DC3000: P. syringae pathovar tomato strain DC3000; Q-Q: Quantile-Quantile; R: Resistance; SA: Salicylic acid; SAR: Systemic acquired resistance; UPR: Unfolded protein response; Wt: Wild type
\end{abstract}

\section{Acknowledgements}

Any work dependent on open-source software owes debt to those who developed these tools. The authors thank everyone involved with free software, from the core developers to those who contributed to the documentation. Many thanks to the authors of the freely available libraries for making this work possible. Some of the authors are supported in part by the Government of Canada via the International Development Research Centre (IDRC) through the African Institute for Mathematical Sciences - Next Einstein Initiative (AIMS-NEI).

\section{Funding}

This research received no specific grant from any funding agency in the public, commercial, or not-for-profit sectors.

\section{Availability of data and materials}

Experimental datasets from Arabidopsis wild type and npr 1 mutant plants used in this study have been uploaded together with this manuscript as Additional file 1.

\section{Authors' contributions}

Conceived and designed the study: GKM REY. Performed the experiments: REY. Analyzed the data: GKM EG ERC. Contributed reagents/materials/analysis tools: GKM EG ERC. Wrote the paper: GKM EG REY. Approved the final version of the paper: GKM.

\section{Ethics approval and consent to participate}

Not applicable.

\section{Consent for publication \\ Not applicable.}

\section{Competing interests}

The authors declare that they have no competing interests.

\section{Publisher's Note}

Springer Nature remains neutral with regard to jurisdictional claims in published maps and institutional affiliations.

\section{Author details}

${ }^{1}$ African Institute for Mathematical Sciences (AIMS), AIMS South Africa and AIMS Ghana, Cape Town, South Africa. ${ }^{2}$ Biomathematics Division, Department of Mathematical Sciences, Stellenbosch University, Stellenbosch, South Africa. ${ }^{3}$ Computational Biology Division, Department of Integrative Biomedical Sciences, Institute of Infectious Disease and Molecular Medicine, University of Cape Town, Medical School, Anzio Road, 7925, Observatory, Cape Town, South Africa. ${ }^{4}$ Division of Human Genetics, Department of Pathology, Institute of Infectious Disease and Molecular Medicine, University of Cape Town, Medical School, Anzio Road, Observatory, 7925, Cape Town, South Africa.

Received: 30 November 2016 Accepted: 7 November 2017

Published online: 23 November 2017

\section{References}

1. Dudnik A, Dudler R. Genomics-based exploration of virulence determinants and host-specific adaptations of pseudomonas syringae strains isolated from grasses. Pathogens. 2014;3:121-48.

2. Nürnberger T, Brunner F, Kemmerling B, Piater L. Innate immunity in plants and animals: striking similarities and obvious differences. Immunol Rev. 2004;198:249-66.

3. Lacombe S, Rougon-Cardoso A, Sherwood E, Peeters N, Dahlbeck D, van Esse HP, Smoker M, Rallapalli G, Thomma BP, Staskawicz B, Jones JD, Zipfel C. Interfamily transfer of a plant pattern-recognition receptor confers broad-spectrum bacterial resistance. Nat Biotechnol. 2010;28(4): 365-9.

4. Zhang J, Zhou JM. Plant immunity triggered by microbial molecular signatures. Mol Plant. 2010;3(5):783-93.

5. Bonas U, Van den Ackerveken G. Gene-for-gene interactions: bacterial avirulence proteins specify plant disease resistance. Curr Opin Microbiol. 1999;2(1):94-8.

6. Liu JX, Srivastava R, Che P, Howell SH. An endoplasmic reticulum stress response in Arabidopsis is mediated by proteolytic processing and nuclear relocation of a membrane-associated transcription factor, bZIP28. Plant Cell. 2007;19:4111-9.

7. Grant M, Lamb C. Systemic immunity. Curr Opin Plant Biol. 2006;9(4): 414-20.

8. Pieterse C, van Loon LC. Salicylic acid-independent plant defence pathways. Trends Plant Sci. 1999;4(2):52-8.

9. Delaney TP, Friedrich L, Ryals JA. Arabidopsis signal transduction mutan defective in chemically and biologically induced disease resistance. Proc Natl Acad Sci. 1995;92(14):6602-6.

10. Glazebrook J, Zook M, Mert F, Kagan I, Rogers EE, Crute IR, Holub EB, Hammerschmidt R, Ausubel FM. Phytoalexin-Deficient Mutants of Arabidopsis Reveal That Pad4 Encodes a Regulatory Factor and That Four Pad Genes Contribute to Downy Mildew Resistance. Genetics. 1997;146(1):381-92.

11. Cao H, Glazebrook J, Clarke J, Volko S, Dong X. The Arabidopsis NPR1 gene that controls systemic acquired resistance encodes a novel protein containing ankyrin repeats. Cell. 1997;88:57-63.

12. Draper J. Salicylate, superoxide synthesis and cell suicide in plant defense. Trends Plant Sci. 1997;2:162-5. 
13. Overmyer K, Brosché M, Kangasjärvi J. Reactive oxygen species and hormonal control of cell death. Trends Plant Sci. 2003;8(7):335-42.

14. Verma V, Ravindran P, Kumar P. Plant hormone-mediated regulation of stress responses. BMC Plant Biol. 2016;16:86.

15. Windram O, Denby KJ. Modelling signaling networks underlying plant defence. Curr Opin Plant Biol. 2015;27:165-71.

16. Fischer AM. The Complex Regulation of Senescence. Crit Rev Plant Sci. 31(2):124-147.

17. Katagiri F, Thilmony R, He SY. The Arabidopsis Thaliana-Pseudomonas Syringae Interaction. Arabidopsis Book. 2002;1:0039.

18. Moore LW. Pseudomonas syringae: Disease and Ice Nucleation Activity. Ornamentals Northwest. 1988;12(2):3.

19. Buell CR, Joardar V, Lindeberg M, Selengut J, Paulsen IT, Gwinn ML, Dodson RJ, Deboy RT, Durkin AS, Kolonay JF, Madupu R, Daugherty S, Brinkac L, Beanan MJ, Haft DH, Nelson WC, Davidsen T, Zafar N, Zhou L, Liu J, Yuan Q, Khouri H, Fedorova N, Tran B, Russell D, Berry K, Utterback T, Van Aken SE, Feldblyum TV, D'Ascenzo M, Deng WL, Ramos AR, Alfano JR, Cartinhour S, Chatterjee AK, Delaney TP, Lazarowitz SG, Martin GB, Schneider DJ, Tang X, Bender CL, White O, Fraser CM, Collmer A. The complete genome sequence of the arabidopsis and tomato pathogen Pseudomonas syringae pv. tomato DC3000. Proc Natl Acad Sci. 2003;100(18):10181-6.

20. The Arabidopsis Genome Initiative. Analysis of the genome sequence of the flowering plant arabidopsis thaliana. Nature. 2000;408(6814): 796-815.

21. Sahu SS, Weirick T, Kaundal R. Predicting genome-scale arabidopsis-pseudomonas syringae interactome using domain and interolog-based approaches. BMC Bioinformatcis. 2014;15(Suppl 11):13.

22. Bevan M, Walsh S. The Arabidopsis Genome: A Foundation for Plant Research. Genome Res. 2005;15(12):1632-42.

23. Durrant W, Dong X. Systemic Acquired Resistance. Annu Rev Phytopathol. 2004;42:185-209.

24. Lin R, Wang H. Arabidopsis FHY3/FAR1 gene family and distinct roles of its members in light control of Arabidopsis development. Plant Physiol. 2004; 136:4010-022.

25. Makandar R, Essig JS, Schapaugh MA, Trick HN, Shah J. Genetically engineered resistance to Fusarium head blight in wheat by expression of Arabidopsis NPR1. Mol Plant-Microbe Interact. 2006;19:123-9.

26. Endah R, Beyene G, Kiggundu A, van den Berg N, Schluter U, Kunert K, Chikwamba R. Elicitor and Fusarium-induced expression of NPR1-like genes in banana. Plant Physiol Biochem. 2008;46:1007-14.

27. Quilis J, Peñas G, Messeguer J, Brugidou C, San Segundo B. The Arabidopsis AtNPR1 inversely modulates defense responses against fungal, bacterial, or viral pathogens while conferring hypersensitivity to abiotic stresses in transgenic rice. Mol Plant Microbe Interact. 2008;21(9): 1215-1231.

28. Zhao H, Dai T, Jiang D, Cao W. Effects of high temperature on key enzymes involved in starch and protein formation in grains of two wheat 1320 cultivars. J Agron Crop Sci. 2008;194:47-54.

29. Wally O, Jayaraj J, Punja Z. Comparative resistance to foliar fungal pathogens in transgenic carrot plants expressing genes encoding for chitinase, $\beta$-1,3-glucanase and peroxidise. Eur J Plant Pathol. 2009;123: 331-42.

30. Parkhi V, Kumar V, Campbell LM, Bell AA, Shah J, Rathore KS. Resistance against various fungal pathogens and reniform nematode in transgenic cotton plants expressing Arabidopsis NPR1. Transgenic Res. 2010;19(6):959-75.

31. Shi Z, Maximova SN, Liu Y, Verica J, Guiltinan MJ. Functional Analysis of the Theobroma Cacao NPR1 Gene in Arabidopsis. BMC Plant Biol. 2010;10(1):248

32. Yocgo RE, Creissen G, Kunert K, Chikwamba R. Two different banana npr1-like coding sequences confer similar protection against pathogens in Arabidopsis. Tropical Plant Biol. 2012;5:309-16.

33. Mauch-Mani B, Mauch F. The Role of Abscisic Acid in Plant-Pathogen Interactions. Curr Opin Plant Biol. 2005;8(4):409-14.

34. Fan J, Crooks C, Lamb C. High throughput quantitative luminescence assay of the growth in planta of Pseudomonas syringae chromosomally tagged with Photorhabdus luminescens lux-CDABE. Plant J. 2008;53:393-9.

35. Meng L, Huang R, Gu J. A Review of Semantic Similarity Measures in WordNet. Int J Hybrid Inf Technol. 2013;6(1):1-12.

36. Mazandu GK, Chimusa ER, Mulder NJ. Expressions of different semantic similarity measures in the context of biomedical sciences and WordNet. Brief Bioinform (Supplementary Material). 2016;18(5):886-901.
37. Howell DC. Statistical Methods for Psychology, 6th edition. Belmont: Thomson Wadsworth; 2007, pp. 318-24.

38. Tabachnick BG, Fidell LS. Using Multivariate Statistics, 5th edition. Boston: Allyn and Bacon; 2007, pp. 86-9.

39. Doane DP, Seward LE. Measuring skewness: A forgotten statistic? J Stat Educ. 2011;19(2):1-18.

40. Ashburner M, Ball CA, Blake JA, Botstein D, Butler H, Cherry JM, Davis AP, Dolinski K, Dwight SS, Eppig JT, Harris MA, Hill DP, Issel-Tarver L, Kasarskis A, Lewis S, Matese JC, Richardson JE, Ringwald M, Rubin GM, Sherlock G. Gene Ontology: tool for the unification of biology. Nat Genet. 2000;25(1):25-9.

41. Consortium GO, et al. The Gene Ontology in 2010: Extensions and Refinements. Nucleic Acids Res. 2010;38(suppl 1):331-5.

42. Camon E, Magrane M, Barrell D, Lee V, Dimmer E, Maslen J, Binns D, Harte N, Lopez R, Apweiler R. The Gene Ontology Annotation (GOA) Database: sharing knowledge in uniprot with Gene Ontology. Nucleic Acids Res. 2004;32:262-6.

43. Barrell D, Dimmer E, Huntley RP, Binns D, O'Donovan C, Apweiler R. The GOA database in 2009-an integrated Gene Ontology Annotation resource. Nucleic Acids Res. 2009;37:396-403.

44. Huntley RP, Sawford T, Mutowo-Muellenet P, Shypitsyna A, Bonilla C, Martin MJ, O'Donovan C. The GOA database: Gene Ontology annotation updates for 2015. Nucleic Acids Res. 2014;43:1057-63.

45. Mazandu GK, Mulder NJ. Generation and analysis of large-scale data-driven Mycobacterium tuberculosis functional networks for drug target identification. Adv Bioinformatics. 2011;2011:801478.

46. Mulder NJ, Akinola RO, Mazandu GK, Rapanoël HA. Using biological networks to improve our understanding of infectious diseases. CSBJ. 2014;11(18):1-10.

47. Mazandu GK, Mulder NJ. The Use of Semantic Similarity Measures for Optimally Integrating Heterogeneous Gene Ontology Data from Large Scale Annotation Pipelines. Front Genet. 2014;5;5:264.

48. Mazandu GK, Mulder NJ. A Topology-Based Metric for Measuring Term Similarity in the Gene Ontology. Adv Bioinforma. 2012;2012:975783.

49. Mazandu GK, Mulder NJ. Information Content-based Gene ontology Semantic Similarity Approaches: Toward a Unified Framework Theory. BioMed Res Int. 2013;2013:292063.

50. Mazandu GK, Mulder NJ. Information Content-Based Gene Ontology Functional Similarity Measures: Which One to Use for a Given Biological Data Type? PLoS ONE. 2014;9(12):113859.

51. Mazandu GK, Chimusa ER, Mbiyavanga M, Mulder NJ. A-DaGO-FUN: an adaptable gene ontology semantic similarity-based functional analysis tool. Bioinformatics. 2015;32(3):477-9.

52. Mazandu GK, Chimusa ER, Mulder NJ. Gene Ontology semantic similarity tools: Survey on features and challenges for biological knowledge discovery. Brief Bioinform. 2016;18(5):886-901.

53. Montañez G, Cho YR. Predicting false positives of protein-protein interaction data by semantic similarity measures. Curr Bioinforma. 2013;8(3):339-46.

54. Mazandu GK, Mulder NJ. Function Prediction and Analysis of Mycobacterium Tuberculosis Hypothetical Proteins. Int J Mol Sci. 2012;13(6):7283-302.

55. Mazandu GK, Mulder NJ. DaGO-Fun: Tool for Gene Ontology-based Functional Analysis Using Term Information Content Measures. BMC Bioinformatics. 2013;14(1):284.

56. Cao H, Bowling SA, Gordon AS, XD. Characterization of an arabidopsis mutant that is non-responsive to inducers of systemic acquired resistance. Plant Cell. 1994;6:1583-92.

57. Rangaswamy R. Text Book of Agricultural Statistics. Chapter 13, A. New Delhi: New age international publishing (P) Limited Publishers; 1995, p. 127.

58. Cao H, Li X, Dong X. Generation of broad-spectrum disease resistance by overexpression of an essential regulatory gene in systemic acquired resistance. Proc Natl Acad Sci. 1998;95:6531-536.

59. Mou Z, Fan W, Dong X. Inducers of plant systemic acquired resistance regulate NPR1 function through redox changes. Cell. 2003;113(7): 935-44.

60. Hong-Zhi Z, Xin-Zhong C. Nonexpressor of pathogenesis-related genes 1 (NPR1): a key node of plant disease resistance signalling network. Chin J Biotechnol. 2005;21(4):511-5.

61. UnitProt-Consortium, Retrieve/ID Mapping. http://www.uniprot.org/ uniprot/. Accessed 11 Oct 2016. 
62. UniProt-GOA. http://www.ebi.ac.uk/GOA/arabidopsis_release. Accessed 11 Oct 2016

63. Wang L, Tsuda K, Sato M, Cohen JD, Katagiri F, Glazebrook J. Arabidopsis CaM Binding Protein CBP60g Contributes to MAMP-Induced SA Accumulation and Is Involved in Disease Resistance against Pseudomonas syringae. PLoS Pathogens. 2009;5(2):1000301.

64. Wang L, Tsuda K, Truman W, Sato M, Nguyen LV, Katagiri F, Glazebrook J. CBP60g and SARD1 play partially redundant critical rolesin salicylic acid signaling. Plant J. 2011;67:1029-41.

65. Seyfferth C, Tsuda K. Salicylic acid signal transduction: the initiation of biosynthesis, perception and transcriptional reprogramming. Front Plant Sci. 2014;5:697.

66. Ren H, Gu G, Long J, Yin Q, Wu T, Song T, Zhang S, Chen Z, Dong H. Combinative effects of a bacterial type-III effector and a biocontrol bacterium on rice growth and disease resistance. J Biosci. 2006;31(5): 617-27.

67. Bethke G, Pecher P, Eschen-Lippold L, Tsuda K, Katagiri F, Glazebrook J, Scheel D, Lee J. Activation of the Arabidopsis thaliana mitogen-activated protein kinase MPK11 by the flagellin-derived elicitor peptide, flg22. Mol Plant Microbe Interact. 2012;25:471-80.

68. Kovtun Y, Chiu WL, Tena G, Sheen J. Functional analysis of oxidative stress-activated mitogen-activated protein kinase cascade in plants. Proc Natl Acad Sci. 2000;97:2940-950.

69. Kim SH, Woo DH, Kim JM, Lee SY, Chung WS, Moon YH. Arabidopsis MKK4 mediates osmotic-stress response via its regulation of MPK3 activity. Biochem Biophys Res Commun. 2011:412(1):150-4.

70. Perochon A, Aldon D, Galaud JP, Ranty B. Calmodulin and calmodulin-like proteins in plant calcium signaling. Biochimie. 2011;93(12):2048-053.

71. Cheval C, Aldon D, Galaud JP, Ranty B. Calcium/calmodulin-mediated regulation of plant immunity. Biochim Biophys Acta. 2013;1833(7): 1766-1771.

72. Knight $H$, Knight MR. Abiotic stress signaling pathways: specificity and cross-talk. Trends Plant Sci. 2001;6:262-7.

73. Sanders D, Pelloux J, Brownlee C, Harper JF. Calcium at the crossroads of signaling. Plant Cell. 2002;14(suppl 1):401-17.

74. Clarke JD, Aarts N, Feys BJ, Dong X, Parker JE. Constitutive disease resistance requires EDS1 in the arabidopsis mutants cpr1 and cpr6 and is partially EDS1-dependent in cpr5. Plant J. 2001:26(4):409-20.

75. Falk A, Feys BJ, Frost LN, Jones JDG, Daniels MJ, Parker JE. EDS1, an essential component of $\mathrm{R}$ gene mediated disease resistance in arabidopsis, has homology to eukaryotic lipases. PNAS Plant Bio. 1999;96:3292-7.

76. Eulgem T. Regulation of the arabidopsis defence transcriptome. Trends Plant Sci. 2005;10:71-8.

77. Mindrinos M, Katagiri F, Yu GL, Frederick M, Ausubel FM. The A thaliana disease resistance gene RPS2 encodes a protein containing a nucleotide-binding site and leucine-rich repeats. Cell. 1994;78(6):1089-99.

78. Axtell MJ, Staskawicz BJ. Initiation of RPS2-specified disease resistance in Arabidopsis is coupled to the AvrRpt2-directed elimination of RIN4. Cell. 2003;112(3):369-77.

79. Zheng MS, Takahashi H, Miyazaki A, Hamamoto H, Shah J, Yamaguchi I, Kusano T. Up-regulation of Arabidopsis thaliana NHL10 in the hypersensitive response to Cucumber mosaic virus infection and in senescing leaves is controlled by signalling pathways that differ in salicylate involvement. Planta. 2004;218(5):740-50.

80. Morita-Yamamuro C, Tsutsui T, Sato M, Yoshioka H, Tamaoki M, Ogawa D, Matsuura H, Yoshihara T, Ikeda A, Uyeda I, Yamaguchi J. Controls programmed cell death in the plant immune system and encodes a protein containing a MACPF domain. Plant Cell Physiol. 2005;46(6):902-12.

81. Vierstra RD. Proteolysis in plants: mechanisms and functions. Plant Mol Biol. 1996:32(1-2):275-302.

82. Dreher K, Callis J. Ubiquitin, hormones and biotic stress in plants. Ann Bot. 2007:99(5):787-822.

83. Spoel SH, Koornneef A, Claessens SM, Korzelius JP, Van Pelt JA, Mueller MJ Buchala AJ, Métraux JP, Brown R, Kazan K, Van Loon LC, Dong X, Pieterse CMJ. NPR1 modulates cross-talk between salicylate- and jasmonate-dependent defense pathways through a novel function in the cytosol. Plant Cell. 2003;15:760-70.

84. Kinkema M, Fan W, Dong X. Nuclear localization of NPR1 is required for activation of pr gene expression. Plant Cell. 2000;12(12):2339-350.
85. Cho BH, Smedegaard-Petersen $\mathrm{V}$. Induction of resistance to erysiphe graminis f. sp. hordei in near isogenic barley lines. Phytopathology. 1986;76:301-5.

86. Joazeiro CA, Weissman AM. RING finger proteins: mediators of ubiquitin ligase activity. Cell. 2000;102(5):549-52.

87. Galvão RM, Kota U, Soderblom EJ, Goshe MB, Boss WF. Characterization of a new family of protein kinases from arabidopsis containing phosphoinositide 3/4-kinase and ubiquitin-like domains. Biochem J. 2008;409(1):117-27.

88. Salinas-Mondragón RE, Garcidueñas-Piña C, Guzmán P. Early elicitor induction in members of a novel multigene family coding for highly related RING-H2 proteins in Arabidopsis thaliana. Plant Mol Biol. 1999:40(4):579-90.

89. Krinke O, Ruelland E, Valentová O, Vergnolle C, Renou JP, Taconnat LMF, Burketová L, Zachowski A. Phosphatidylinositol 4-kinase activation is an early response to salicylic acid in arabidopsis suspension cells. Plant Physiol. 2007;144(3):1347-59.

90. Yuan X, Zhang S, Liu S, Yu M, Su H, Shu H, Li X. Global analysis of ankyrin repeat domain C3HC4-Type RING Finger gene family in plants. PLOS ONE. 2013;8(3):58003.

91. Becerra $C$, Jahrmann T, Puigdomènech P, Vicient CM. Ankyrin repeat-containing proteins in Arabidopsis: characterization of a nove and abundant group of genes coding ankyrin-transmembrane proteins. Gene. 2004;340(1):111-21.

92. Rochon A, Boyle P, Wignes T, Fobert PR, Despres C. The coactivator function of Arabidopsis NPR1 requires the core of its BTB/POZ domain and the oxidation of C-terminal cysteines. Plant Cell. 2006;18:3670-685.

93. Ryals J, Weymann K, Lawton K, Friedrich L, Ellis D, Steiner HY, Johnson J, Delaney TP, Jesse T, Vos P, Uknes S. The Arabidopsis nim 1 protein shows homology to the mammalian transcription factor inhibitor $\left.\right|_{\kappa}$ B. Plant Cell. 1997;9(3):425-39.

94. Zhou JM, Trifa Y, Silva H, Pontier D, Lam E, Shah J, Klessig DF. NPR1 differentially interacts with members of the TGA/OBF family of transcription factors that bind an element of the PR-1 gene required for induction by salicylic acid. Mol Plant-Microbe Interact. 2000;13:19-202.

95. Zhang YL, Tessaro MJ, Lassner M, Li X. Knockout analysis of Arabidopsis transcription factors TGA2, TGA5, and TGA6 reveals their redundant and essential roles in systemic acquired resistance. Plant Cell. 2003;15: 2647-653.

96. Després C, DeLong C, Glaze S, Liu E, Fobert PR. The Arabidopsis NPR1/NIM1 protein enhances the DNA binding activity of a subgroup of the TGA family of bZIP transcription factors. Plant Cell. 2000;12:279-90.

97. Pieterse CMJ, Van Loon LC. NPR1: the spider in the web of induced resistance signaling pathways. Curr Opin Plant Biol. 2004;7:456-64.

98. Deppmann CD, Acharya A, Rishi V, Wobbes B, Smeekens S, Taparowsky EJ, Vinson C. Dimerization specificity of all 67 B-ZIP motifs in Arabidopsis thaliana: A comparison to Homo sapiens B-ZIP motifs. Nucleic Acids Res. 2004;32:3435-445.

99. Moreno AA, Mukhtar MS, Blanco F, Boatwright JL, Moreno I, Jordan MR, Chen Y, Brandizzi F, Dong X, Orellana A, Pajerowska-Mukhtar KM. IRE1/bZIP60-mediated unfolded protein response plays distinct roles in plant immunity and abiotic stress responses. PLoS ONE. 2012;7(2):31944.

100. Liu JX, Howell SH. bZIP28 and NF-Y Transcription Factors Are Activated by ER Stress and Assemble into a Transcriptional Complex to Regulate Stress Response Genes in Arabidopsis. Plant Cell. 2010;22(3):782-96.

101. Eulgem T, Rushton PJ, Robatzek S, Somssich IE. The WRKY superfamily of plant transcription factors. Trends Plant Sci. 2000;5:199-206.

102. Xu X, Chen C, Fan B, Chen Z. Physical and functional interactions between pathogen-induced arabidopsis WRKY18, WRKY40, and WRKY60 transcription factors. Plant Cell. 2006;18(5):1310-26.

103. Chen W, Chi Y, Taylor NL, Lambers H, Finnegan PM. Disruption of ptLPD1 or ptLPD2, genes that encode isoforms of the plastidial lipoamide dehydrogenase, confers arsenate hypersensitivity in Arabidopsis. Plant Physiol. 2010;153:1385-97.

104. Li J, Brader G, Palva ET. The WRKY70 transcription factor: a node of convergence for jasmonate-mediated and salicylate-mediated signals in plant defence. Plant Cell. 2004;16:319-31.

105. Louis J, Gobbato E, Mondal HA, Feys BJ, Parker JE, Shah J. Discrimination of arabidopsis pad4 activities in defense against green peach aphid and pathogens. Plant Physiol. 2012;158:186-72. 
106. Jirage $D$, Tina $L$, Tootle $T$, Reuber $L$, Frost $L N$, Feys $B J$, Parker $J E$, Ausubel J., abd Glazebrook FM. Arabidopsis thaliana PAD4 encodes a lipase-like gene that is important for salicylic acid signaling. Proc Natl Acad Sci. 1999;96(23):13583-88.

107. Jirage D, Zhou N, Cooper B, Clarke JD, Dong X, Glazebrook J. Constitutive salicylic acid-dependent signaling in cpr1 and cpr6 mutants requires PAD4. Plant J. 2001;26:395-407.

108. Weigel RR, Bäuscher C, Pfitzner AJP, Pfitzner UM. NIMIN-1, NIMIN-2 and NIMIN-3, members of a novel family of proteins from Arabidopsis that interact with NPR1/NIM1, a key regulator of systemic acquired resistance in plants. Plant Mol Biol. 2001;46:143-60.

109. Weigel RR, Pfitzner UM, Gatz C. Interaction of NIMIN1 with NPR1 modulates PR gene expression in Arabidopsis. Plant Cell. 2005;17: 1279-91.

110. Glazebrook J. Contrasting mechanisms of defense against biotrophic and necrotrophic pathogens. Ann Rev Phytopathol. 2005;43:205-27.

111. McDowell JM, Dangl JL. Signal transduction in the plant immune response. Trends Biochem Sci. 2000;25:79-82.

112. Plotnikov A, Zehorai E, Procaccia S, Seger R. The MAPK cascades: signaling components, nuclear roles and mechanisms of nuclear translocation. Biochim Biophys Acta. 2011;1813(9):1619-33.

113. Salazar GA, Meintjes A, Mazandu GK, Rapanoël HA, Akinola RO, Mulder NJ. A web-based protein interaction network visualizer. BMC Bioinformatics. 2014;15:129.

114. Schwikowski B, Ideker T. Cytoscape: A Software Environment for Integrated Models of Biomolecular Interaction Networks. Genome Res. 2003;13:2498-504.

115. Hubbard KE, Nishimura N, Hitomi K, Getzoff ED, Schroeder Jl. Early Abscisic Acid Signal Transduction Mechanisms: Newly Discovered Components and Newly Emerging Questions. Genes Dev. 2010;24(16): 1695-1708.

\section{Submit your next manuscript to BioMed Central and we will help you at every step:}

- We accept pre-submission inquiries

- Our selector tool helps you to find the most relevant journal

- We provide round the clock customer support

- Convenient online submission

- Thorough peer review

- Inclusion in PubMed and all major indexing services

- Maximum visibility for your research

Submit your manuscript at www.biomedcentral.com/submit 